\title{
SUSTENTABILIDADE, GLOBALIZAÇÃO ECONÔMICA E A ASCENSÃO DO CAPITALISMO VERDE
}

\author{
Maurício Pedroso Flores ${ }^{1}$ \\ Luiz Ernani Bonesso de Araujo ${ }^{2}$ \\ Jerônimo Siqueira Tybusch ${ }^{3}$
}

\begin{abstract}
Resumo
Diante da presente crise ecológica, intimamente ligada à crise institucional do sistema capitalista, o desenvolvimento sustentável coloca-se como tema premente das agendas políticas dos Estados e da sociedade civil. Observa-se a emergência de diversos atores derivados da globalização que apresentam divergências na concepção de sustentabilidade. A lógica econômica procura se estabelecer dentro desse discurso apropriando-se da razão ambiental, através das práticas ecoeficientes do capitalismo verde. Tal método ignora as múltiplas dimensões da sustentabilidade e as noções de democracia e equidade que esta carrega. A racionalidade econômica no tratamento das questões ambientais acaba por acentuar as desigualdades e dificulta os projetos de uma governança global em torno do meio ambiente, como atestam os fracassos das conferências climáticas realizadas pela ONU.
\end{abstract}

Palavras-chave: globalização, sustentabilidade, desenvolvimento, capitalismo.

\section{INTRODUÇÃO}

Desde que passou a desempenhar um papel fundamental nas democracias liberais, a questão ecológica deu vazão a políticas e iniciativas que visam conciliar a noção capitalista de desenvolvimento - de cunho imediatista e essencialmente econômico - com a proteção dos bens naturais e da qualidade de vida dos indivíduos, dentro de uma perspectiva multidimensional.

A ideia de um "desenvolvimento sustentável" definida pelo Relatório Brundtland $^{4}$ expressou a necessidade de se repensar a atividade econômica dominante, passando-se a levar em conta o resultado negativo das interações do homem com a natureza. Se por um lado o conceito reflete um entendimento de que "o meio ambiente não é apenas uma questão de preservação passiva, mas também de busca ativa" (SEN,

\footnotetext{
${ }^{1}$ Autor. Acadêmico do Curso de Direito da Universidade Federal de Santa Maria (UFSM). Bolsista FIPEUFSM. Integrante do Grupo de Pesquisa em Direito da Sociobiodiversidade (GPDS/UFSM). E-mail: mauriciopflores@gmail.com

${ }^{2}$ Orientador. Doutor em Direito, Professor de Direito Agrário e Ambiental e Chefe de Departamento do Curso de Direito da Universidade Federal de Santa Maria (UFSM). Pesquisador do Grupo de Pesquisa em Direito da Sociobiodiversidade (GPDS/UFSM).

${ }^{3}$ Orientador. Professor Adjunto do quadro efetivo da Universidade Federal de Santa Maria - UFSM. Doutor pela Universidade Federal de Santa Catarina - UFSC. Pesquisador do Grupo de Pesquisa em Direito da Sociobiodiversidade (GPDS/UFSM).

${ }^{4}$ De acordo com o relatório, desenvolvimento sustentável é aquele que satisfaz as necessidades do presente sem comprometer as gerações futuras. (UN, 1987)
} 
2011, p.283), por outro condena a insustentabilidade do modelo econômico neoliberal, ao tratar a natureza como mera externalidade do processo produtivo.

Tendo em vista a emergência de novos atores sociais derivados dos processos de globalização, cujos interesses se expressam de forma diversificada, a concepção de sustentabilidade ganhou interpretações e finalidades distintas. Abre-se então um vasto campo de discussões em torno da conceituação mais precisa do termo. Enquanto as forças dominantes do capital apropriaram-se da razão ambiental como forma de legitimação social, os movimentos sociais interpretaram o discurso da sustentabilidade à luz de um ponto de vista contra hegemônico e em defesa de uma distribuição equitativa dos recursos naturais.

Como resultado, hoje a questão ambiental encontra-se dividida basicamente em duas posições. A primeira, de caráter empresarial, é representada pelo chamado capitalismo verde, que se baseia numa responsabilidade ambiental tardiamente reconhecida e se estrutura no uso da tecnologia (ecoeficiência) para a consecução de metas programáticas. A segunda posição, contrária à manutenção das bases do sistema capitalista sem que se operem mudanças substanciais, é uma abordagem calcada na justiça ambiental, "que se estrutura na defesa dos direitos sociais e ambientais dos grupos que são vítimas da face excludente da dialética do "progresso"” (BOCAYUVA, 2012, p.34). Para essa posição, o desenvolvimento sustentável é visto como uma oportunidade de combater os vícios de um desenvolvimento econômico cego impulsionado à custa da desigualdade social.

Merece destaque, no contexto da globalização, a apropriação da razão ambiental por parte de agentes econômicos privados, como as corporações, e a formação de uma metodologia adequada aos seus interesses no âmbito político, com efeitos diretos para as concepções de democracia e de desenvolvimento inseridos na proposta original da sustentabilidade.

\section{A apropriação econômica da razão ambiental}

Uma das características mais notáveis da globalização foi o deslocamento de poder operado por ela. Os estados-nação assistiram a perda de sua antiga soberania enquanto as entidades econômicas não estatais, consequentemente, provaram de uma liberdade nunca antes vista. Para a economia de mercado, a globalização significou, 
entre outras coisas, a mobilidade necessária para o capital flutuar dentro dos territórios estatais sem estar necessariamente vinculado a eles. Sendo os ganhos capitais o principal objetivo dessas entidades, “os dirigentes das empresas não têm nenhuma necessidade de lutar por metas mais amplas, grandiosas e ambíguas, como o bem-estar geral ou o bem público - eles podem ser guiados unicamente por motivos egoístas." (DAHL, 2001, p.184). As forças econômicas não necessitam assim de obrigações sociais para com seus empregados, com as comunidades ou com as gerações futuras.

Tal liberdade do capital, no entanto, não há de ser plena. Os debates acerca da questão ecológica, intensificados no último quarto do século passado, colocaram-na como mais um limite - além dos sociais e econômicos já existentes - ao sistema global de livre comércio e o modelo desarrazoado de desenvolvimento. Beck (1997) ressalta a evolução realizada a partir de um estágio anterior da modernidade - onde os efeitos colaterais da atividade industrial passam a existir, mas ainda não são considerados problemas sociais que demandem a participação democrática - para uma fase posterior, que se dá quando "os perigos da sociedade industrial começam a dominar os debates e conflitos públicos, tanto políticos como privados.” (BECK, 1997, p.15)

As organizações sociais relacionadas ao movimento ambientalista das décadas de 60 e 70 foram propulsoras de uma mudança nas políticas estatais de regulação da atividade econômica que afetaram, ainda que de forma sutil, a sociedade industrial. A concepção de sustentabilidade

[...] emerge no discurso teórico e político da globalização econômico-ecológica como a expressão de uma lei-limite da natureza diante da autonomização da lei estrutural do valor. A crise ambiental veio questionar os fundamentos ideológicos e teóricos que impulsionaram e legitimaram o crescimento econômico, negando a natureza e a cultura, deslocando a relação entre o Real e o Simbólico. (LEFF, 2006, p.133)

À medida que a articulação dos movimentos ligados à causa ecológica crescia localmente e também globalmente ${ }^{5}$, já não era mais possível e nem mesmo do interesse das organizações empresariais negar uma crise ecológica demasiado evidente, ocultando sua responsabilidade na deterioração dos recursos naturais e da qualidade de vida na Terra. A ideia de risco - de uma catástrofe ambiental, no caso - impregnou a sociedade

\footnotetext{
${ }^{5}$ O Greenpeace e o WWF (World Wide Fund for Nature) são bons exemplos de ativismo ambiental em redes globais.
} 
pragmática a respeito dos bens naturais. Dá-se origem a um processo de operacionalização da natureza, na intenção de protegê-la do modo mais rentável possível. A lógica da racionalidade econômica nos diz que

Tudo deve ser sacrificado a uma geração operacional das coisas. A produção, já não é a Terra que produz nem o trabalho que cria a riqueza (as famosas núpcias da Terra e do trabalho); é o Capital que faz produzir a Terra e o trabalho. O trabalho já não é uma ação, é uma operação. O consumo já não é gozo puro e simples dos bens, é um fazer-gozar, uma operação modelizada e indexada pela gama diferencial dos objetos-signos. (BAUDRILLARD, 1990, p.53)

\section{A questão ecológica na sociedade de consumo}

Uma das dificuldades em se opor a questão ambiental à atual lógica de mercado reside na distinta noção de tempo existente entre elas. Enquanto o capital é veloz, "rápido o bastante para se manter permanentemente um passo adiante de qualquer Estado" (BAUMAN, 1999, p. 63), a razão ambiental remete a um tempo futuro, longínquo demais para que possa ser apreendido na moldura teórica neoclássica. Viver em uma sociedade de consumo implica em aceitar as condições do imediatismo, da efemeridade e da obsolescência programada.

Castells (2010, p.158) alude que o movimento ambientalista, em contrapartida à temporalidade restrita dessa sociedade, propõe a "introdução de uma perspectiva de 'tempo glacial' em nossa temporalidade, nos planos da consciência individual e da política”. Através de uma perspectiva histórica e evolucionária, evoca-se a necessidade de integração dos processos humanos e naturais a fim de que os seres humanos possam resistir à natureza, e não o contrário. ${ }^{7}$ Como impregnar a consciência mercantil de lucros imediatos com a ideia glacial de temporalidade coloca-se então como a questão premente para o ideário do ambientalismo e também da sustentabilidade.

Tendo em vista essa temporalidade aparentemente irreconciliável, o pensamento neoliberal objetivou programá-la a seu modo. Nasce então o chamado capitalismo verde, que consiste em revestir os processos produtivos vigentes como uma carga de preocupação com o futuro do meio ambiente. Num contexto de reconhecimento dos

\footnotetext{
${ }^{7} \mathrm{O}$ entendimento de que o planeta Terra resistirá aos impactos de qualquer ação humana presente ou futura, e que apenas os seres vivos que o habitam - inclusive os humanos - é que sofrerão tais impactos, não é recente. Mesmo entre diversas vertentes, o movimento ambientalista trata-se de um apelo à salvação da humanidade e dos demais seres vivos - não do planeta em si.
} 
danos infringidos à natureza, o modelo do triple bottom line $e^{8}$ ganhou a adesão de grande parte do núcleo empresarial ao aventar a possibilidade de maiores lucros juntamente com uma política de resultados que implica maior responsabilidade ambiental. Tal modelo estimula os consumidores a se tornarem "verdes", ou seja, serem responsáveis em suas escolhas ao optarem por produtos de empresas supostamente comprometidas com a sustentabilidade. O capitalismo verde encaixou-se perfeitamente no interior das grandes empresas, porque deu a elas uma legitimação social necessária em termos mercadológicos. Assistiu-se um multiplicar de etiquetas "verdes" nos produtos, desde itens básicos de alimentação até bens duráveis, como os eletroeletrônicos e os automóveis. A crise ecológica forçou alterações na lógica de consumo, mas em grande parte sem alterar a lógica destruidora que a deu causa.

É possível fazer um paralelo entre a ascensão do capitalismo verde e o já consolidado artifício da filantropia empresarial, que se dá através de ações sociais voltadas a populações carentes e/ou vulneráveis. ${ }^{9}$ Por meio de institutos ou fundações, o setor empresarial assume compromissos de responsabilidade social em relação a temas que deveriam ser objeto de políticas estatais. Inserida na lógica capitalista, a filantropia empresarial, no entanto, transformou-se mais em um diferencial de competitividade do que em verdadeiro compromisso social. Nos termos da sustentabilidade, tornar as empresas "verdes" significou, com o passar do tempo, concedê-las uma espécie de aceitação universal como empresa ambientalmente responsável, mesmo que esta não esteja realmente preocupada com a questão ecológica. Ocorre que

[...] as realizações do trabalho social viram 'produtos' cujo público é formado pelos acionistas e consumidores. Isso pode estar mostrando que a racionalidade econômica dos interesses privados deve comandar bem mais a filantropia empresarial do que o compromisso ético com a sociedade. (PAOLI, 2002, p.395)

O capitalismo verde e a filantropia empresarial aparecem como uma espécie de caminho rumo a um capitalismo mais "civilizado", dotado de preocupações sociais que anteriormente não possuía. No contexto de uma globalização excludente, porém, onde

8 Criado pelo acadêmico e consultor empresarial John Elkington, o termo significa "tripé da sustentabilidade". Aplicado ao mundo corporativo, compreende os resultados sociais, ambientais e econômicos de uma empresa.

${ }^{9}$ Para exemplos, ver Paoli (2002). 
III SEMINÁRII ECOLDGIA

PDLÍTICA

E DIREITO NA AMÉRICA LATINA

e quanto vai para a acumulação de bens adicionais? Em que ponto se deve parar a busca do crescimento material, se se considera que o objetivo último do desenvolvimento é uma civilização do ser e não do ter, e, mais ainda, que a finitude do planeta estabelece um limite para a expansão da produção material? (SACHS, 2008, p.43)

Por sua vez, a concretização do desenvolvimento sustentável para os países do Sul passa por uma diferenciação clara entre crescimento e desenvolvimento. As metas do crescimento econômico, em termos de aumento no PIB, não podem desconsiderar as questões socioambientais que completam a noção multidimensional da sustentabilidade. ${ }^{13} \mathrm{O}$ desafio para os defensores da justiça ambiental constitui-se, nesse caso, em combater as formas perversas de crescimento econômico que assolam as estruturas sociais e dão a falsa impressão de um desenvolvimento includente.

Quanto aos fundamentalistas de mercado, eles implicitamente consideram o desenvolvimento como um conceito redundante. O desenvolvimento virá como resultado natural do crescimento econômico, graças 'ao efeito cascata' (trickle down effect). Não há necessidade de uma teoria do desenvolvimento. Basta aplicar a economia moderna, uma disciplina a-histórica e universalmente válida. (SACHS, 2008, p.26)

Para controlar os prejuízos da ausência de historicismo da econômica capitalista, aponta-se com frequência para a direção do Estado - não com a ilusão de uma soberania recuperada, mas como instrumento regulador da economia. Alguns autores, como Giddens (2010) chegam a sugerir que o aparato estatal deve estar na vanguarda das questões ambientais, sobretudo no que diz respeito às mudanças climáticas. Dentro do território nacional, onde há a dificuldade de uma convergência política, Giddens (2010) sugere que a questão ecológica se sobreponha ao campo de discussões esquerda-direita e se converta em objetivo de um "radicalismo de centro". ${ }^{14}$

Em âmbito internacional, no entanto, os Estados não têm conseguido encontrar soluções que abarquem as diferentes realidades das nações. Poucos avanços foram alcançados desde a Rio-92 até a Rio+20, passando por Bali e Copenhagen. O fracasso dessas conferências se explica, basicamente, pelo fato de que nenhum país ou coalização de países parece ter condição de liderar os debates, já que isso significa

13 Sachs (2008), por exemplo, considera que o desenvolvimento se apoia em cinco pilares: social, ambiental, territorial, econômico e político.

${ }^{14}$ Anthony Giddens dá a entender ser um autor alinhado com as políticas da ecoeficiência e até mesmo com o capitalismo verde. Nos moldes da convergência política, é famoso pelo ideal da "terceira via". 
III SEMINÁRII ECDLOGIA

POLÍTICA

descer um degrau na defesa de seus interesses. A ideia de uma governança global (pelo menos em termos do meio ambiente) naufraga também diante da coerção exercida pelas forças externas ao Estado, que são multiterritoriais. A globalização parece ter derrubado o sonho de uma universalização, ou seja, de uma união global em torno de interesses comuns. O que sobrou da utopia universalizante, de um sentimento de "futuro comum" para todos os habitantes da Terra, é um cenário de intensas desigualdades onde "a liberdade de decidir o futuro está aberta apenas para aqueles que controlam as alternativas e não são obrigados a aceitar imposições.” (ALTVATER, 1999, p.128-129)

\section{CONSIDERAÇÕES FINAIS}

Ao provocar uma revolução na escala espaço-temporal da sociedade moderna, a globalização criou um ambiente propício ao agravamento das desigualdades sociais. A questão ecológica nos mostra que, longe de mudar essa realidade, estamos caminhando para mais uma espécie de exclusão, a ambiental, que se soma à conjuntura socioeconômica. É possível dizer que a causa ecológica é hoje, mais do que nunca, uma causa humana.

Aceito muitas vezes sem reservas por parte de um senso comum desesperado em resolver a problemática ambiental sem modificar as estruturas do poder, o capitalismo verde se mostra apenas como um modo de transformar consumidores - torná-los "verdes". Sendo o direito de escolha na sociedade de consumo metodologicamente insuficiente e restrito a alguns poucos indivíduos - os habitantes do capitalismo "civilizado" - não há como se pensar nas soluções coletivas que o problema exige diante de tais circunstâncias. Com efeito, praticar o desenvolvimento sustentável significa deixar a condição de mero consumidor e estabelecer atitudes verdadeiramente democráticas. Como indica Sachs (2008, p.118), “devemos nos esforçar por desenhar uma estratégia de desenvolvimento que seja ambientalmente sustentável, economicamente sustentada e socialmente includente." Só a participação democrática, inserida num contexto de independência econômica nas relações de poder, parece um caminho viável para a sustentabilidade em suas diferentes dimensões.

Nesse âmbito, os movimentos sociais, com todas as contradições que venham a carregar, surgem como os agentes mais confiáveis para o projeto sustentável. Se 


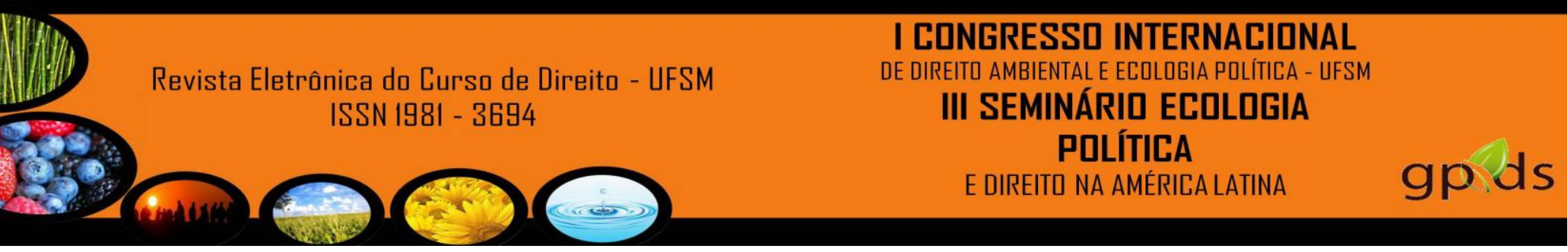

dotados de uma racionalidade ambiental e de uma visão transdisciplinar, eles podem oferecer uma alternativa ao desenvolvimento pautado nos índices de crescimento econômico. Não se trata de desqualificar totalmente a importância de algumas alianças pontuais, como entre ONGs e empresas, ou entre multinacionais e países emergentes. No entanto, é preciso que tais atitudes reflitam um novo paradigma de produção e consumo, repensando o mito do crescimento "em si" e agregando-se à autonomia econômica e epistemológica enunciada pelos movimentos que lutam pela justiça ambiental.

\section{REFERÊNCIAS BIBLIOGRÁFICAS}

ALTVATER, Elmar. Os desafios da globalização e da crise ecológica para o discurso da democracia e dos direitos humanos. In: HELLER, Agnes et al. A crise dos paradigmas sociais e os desafios para o século XXI. Rio de Janeiro: Contraponto, 1999.

BAUDRILLARD, Jean. A Transparência do Mal: ensaio sobre os fenômenos extremos. Campinas: Papirus, 1990.

BAUMAN, Zygmunt. Globalização: as consequências humanas. Rio de Janeiro: Jorge Zahar Ed., 1999.

BECK, Ulrich. A reinvenção da política. In: BECK, Ulrich; GIDDENS, Anthony; LASH, Scott. Modernização reflexiva: política, tradição e estética na ordem social moderna. São Paulo: Editora UNESP, 1997.

BENSUSAN, Nurit. O que a natureza faz por nós: serviços ambientais. In: BENSUSAN, Nurit (org.). Seria melhor mandar ladrilhar?: Biodiversidade, como, para que, por quê. Brasília: Editora UNB, 2009.

BOCAYUVA, Pedro Cláudio. Os desafios da razão ambiental. Le Monde Diplomatique Brasil. São Paulo, ano 5, n. 60, p. 34-35, jul. 2012.

CASTELLS, Manuel. A era da informação: economia, sociedade e cultura. v. 2. O poder da identidade. 7. re. São Paulo: Paz e Terra, 2010.

DAHL, Robert. Sobre a democracia. Brasília: Editora UNB, 2001.

GIDDENS, Anthony. A política da mudança climática. Rio de Janeiro: Zahar, 2010.

LAZZARATO, Maurizio. As revoluções do capitalismo. Trad. Leonora Corsini. Rio de Janeiro: Civilização Brasileira, 2006. 


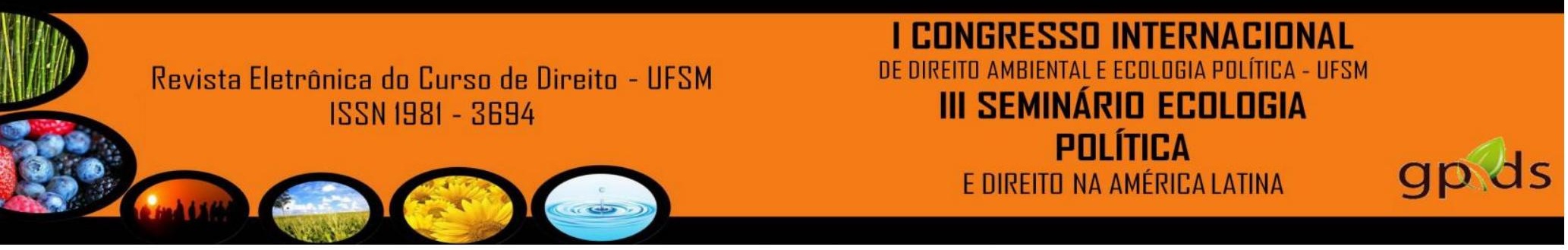

LENZI, Cristiano. A política democrática da sustentabilidade. R. Ambiente \& Sociedade. Campinas, SP, v. XII, n.1, p.19-36, jan./jun. 2009.

LEFF, Enrique. Racionalidade Ambiental: a reapropriação social da natureza. Rio de Janeiro: Civilização Brasileira, 2006.

MARTINEZ-ALIER, Joan. O ecologismo dos pobres. São Paulo: Contexto, 2011.

PAOLI, Maria Célia. Empresas e responsabilidade social: os enredamentos da cidadania no Brasil. In: SANTOS, Boaventura de Sousa (org.). Democratizar a democracia: os caminhos da democracia participativa. Rio de Janeiro: Civilização Brasileira, 2002.

SACHS, Ignacy. Desenvolvimento includente, sustentável, sustentado. Rio de Janeiro: Garamond, 2008.

SEN, Amartya. A ideia de justiça. São Paulo: Companhia das Letras, 2011.

UNITED NATIONS. Our Common Future: Report of the World Commission of Environment and Development. Department of Economic and Social Affairs - UN (DESA), 1987. 